\title{
특발성 척추측만증 환자의 방사선학적 지표와 \\ 폐기능, 홉기 능력의 관계
}

이상길 ${ }^{1)} \cdot$ 오재근 ${ }^{2)} \cdot$ 임승길 $)^{*}$

1) 케이슈로스 2) 한국체육대학교 3) 동신대학교

\begin{abstract}
Lee, Sang-Gil · Oh, Jae-Keun · Lim, Seung-Kil. Relationship between radiological indices, pulmonary function, and inspiratory capacity in idiopathic scoliosis. KINESIOLOGY, 2016, 18(2): 53-62 [PURPOSE] The purpose of this study was to investigate the relationship between radiological indices, pulmonary function, and inspiratory capacity in patients with idiopathic scoliosis after taking into account their age, height, weight, muscle mass, and BMI. [METHODS] We enrolled a total of 31 female patients with mild to moderate, right-sided idiopathic scoliosis. We took standardized standing anteroposterior and lateral radiographs using full spine radiography. The following radiological indices were measured: the thoracic Cobb's angle, the level of shoulder asymmetry, the pelvic tilt, the thoracic kyphotic angle, and the number of vertebra. Pulmonary function was measured as the maximum inspiration volume, and our measures of inspiratory capacity were inspiratory pressure and inspiratory velocity. Pearson's and partial correlation analyses were used to analyze data. [RESULTS] We found that pulmonary function was not significantly correlated with age, height, weight, muscle mass, or BM in patients with mild to moderate idiopathic scoliosis or with a thoracic Cobb's angle of less than $40^{\circ}$. But we found that inspiratory capacity was significantly correlated with these factors save for height $(p<.05)$. After adjusting for these factors, we found that radiological indices were not significantly correlated with either pulmonary function or inspiratory capacity in these patients. [CONCLUSIONS] After adjusting for factors associated with inspiratory capacity, we found that radiological indices in patients with mild to moderate idiopathic scoliosis were not associated with respiratory parameters such as pulmonary function and inspiratory capacity. Therefore, our data suggest giving a consultation of a possible impairment in pulmonary-related function to such patients on the basis of radiological findings such as the Cobb's angle may be ungrounded and should be refrained.
\end{abstract}

Key words : idiopathic scoliosis, Cobb's angle, pulmonary function, inspiratory ability, peak inspiratory flow 주요어 : 특발성 척추측만증, 콥스 각, 폐기능, 흡기 능력, 최대 흡기유속

\section{서론}

척추측만증은 관상면상에서 척추 변형에 의해 발생 된 척추만곡을 측정했을 때, 콥스 각(Cobb's angle)이 $10^{\circ}$ 이상인 경우를 말한다(Green et al., 2009; Kane, 1997). 척추측만증의 유병율은 2 3\% 정도로(Chung, 2007; Weinstein, 1989) 남자보다는 여자 청소년에게 더 높은 비율로 발생한다(An et al., 2015; Chung, 2007). 척추측만증의 정도를 나타내는 콥스 각에 따른 유병율 을 살펴보면, 10 19 사이가 71\%로 가장 많고, 20 29 가 $24 \%, 30 \sim 39^{\circ}$ 가 $4 \%$, 그리고 $40^{\circ}$ 이상인 경우가 $1 \%$ 정도를 차지한다(An et al., 2015). 척추측만증 중에 특
발성 척추측만증은 발생 원인이 확실하지 않은 측만증 을 말하며, 전체 척추측만증의 70 80\% 정도(Machida, 1999; Willner, 1984)로 가장 많은 비율을 차지한다.

척추측만증은 단순히 척주와 흥곽의 외형적 변형만을 야기하는 것이 아니라 폐기능 감소와도 관련되어 있다 (Huh et al., 2015; Upadhyay et al., 1995). 그런데 척추 측만증은 관상면에서의 변형만 일어나는 것이 아니라, 3 차원적인 척추 변형이 일어나는 것이기 때문에 시상면과 횡단면에서의 변형도 함께 일어난다. 하지만 척추측만증 과 폐기능 관련성에 관한 국내 연구는 관상면에서의 변 형과 관련된 콥스 각과 폐활량에 대한 연구(Lee \& Hahn, 1971)만 보고되었을 뿐 시상면에서의 척추 변형과의 관련

* 교신저자. es007-0@hanmail.net 
성은 보고되지 않았다. 국외에서는 이미 시상면과 관련된 변인들과 폐기능의 관련성이 보고되었다. Upadhyay et al.(1995)은 횡단면에서의 척추 변형과 관련된 척추 회전 (vertebral rotation), 시상면에서의 척추 변형과 관련된 흥 추 후만각 등과 폐기능의 관련성에 관해 보고하였으며, Dreimann et al.(2014)도 흥추 후만각과 폐기능과의 관계 를 보고하였다. Newton et al.(2005)은 흥추 만곡의 크기 (magnitude of the thoracic curve), 흥추 만곡과 관련된 척추의 수(number of vertebrae involved in the thoracic curve), 흥추의 저후만(thoracic hypokyphosis), 그리고 관 상면에서의 불균형과 폐기능의 관련성을 보고하였다. 그 러나 이러한 선행연구들(Dreimann et al., 2014; Newton et al., 2005; Upadhyay et al., 1995)은 척추측만증이 매우 심한 환자들을 대상으로 한 연구들이다.

앞서 언급한 것처럼 $40^{\circ}$ 이상의 콥스 각을 가지고 있는 심한 척추측만증 환자들은 전체 척추측만증 환자 의 $1 \%$ 정도로 매우 낮은 비율을 차지한다. $1 \%$ 정도의 낮은 비율을 차지하는 심각한 척추 변형이 있는 환자들 을 대상으로 한 연구결과를 대다수의 경증 중등도 척 추측만증이 있는 환자들에게 보편화하여 적용하는 것은 많은 적절하지 않을 수 있다. 그러나 경증 중등도 척추 측만증과 폐기능 감소의 관련성에 관한 연구(Barrios et al., 2005; Yamaguchi, 1984)는 극히 일부만 진행되었다. 그러나 폐기능은 척추측만증 환자와 관련된 운동학 분 야의 연구들(Lee \& Kim, 2013; Park et al., 2013; Park \& Shim, 2014)에서 주요 변인으로 다루어지고 있다.

척추측만증 환자의 폐기능은 척추의 변형 이외에도 다른 변인들에 의해 영향을 받을 수 있다. Xu et al.(2015)은 BMI가 특발성 척추측만증 환자의 폐기능과 관련된 중요한 지표라고 보고하였다. 이러한 보고를 볼 때, 신장과 체중, 근육량이 폐기능에 영향을 주며, 대상 이 성장기라는 점을 고려해보면 나이와도 관련이 있을 것으로 생각된다. 그러나 척추측만증 환자의 폐기능과 관련된 연구에 있어서 이러한 신체적 변인을 고려한 척추 변형 관련 변인들과의 관계는 보고된 바 없다.

Shen et al.(2010)은 만성 폐쇄성 폐질환 환자의 흡기 량(inspiration capacity)과 삶의 질 간에 유의한 상관관계 가 있다고 하였다. Yetkin \& Gunen(2008)은 만성 폐쇄성 폐질환자의 폐질환의 급성 악화 동안에 흡기 능력은 1 초 간 강제호기량(forced expiratory volume) 보다 유용한
자료라고 하였다. Tantucci et al.(2008)은 만성 폐쇄성 폐 질환자의 호흡기 관련 사망과 가령에 따른 모든 사망원 인, 그리고 증상 악화로 인한 입원을 예측하는데 흡기량 이 중요한 요인이라고 하였다. Kim et al.(2005b)은 척수 손상환자들을 대상으로 규칙적인 흡기근 트레이닝을 적 용한 결과, 척추측만증과 폐기능이 개선되었다고 하였다. 이러한 선행연구(Kim et al., 2005b; Shen et al., 2010; Tantucci et al., 2008; Yetkin \& Gunen, 2008)를 토대로 흡기량은 중요한 폐기능의 하나이며 흡기 능력과 척추측 만증이 관련되어 있을 수도 있다고 판단하였다.

이에 본 연구는 특발성 척추측만증 환자의 대부분 을 차지하며, 운동학 분야에서 운동치료적 접근이 이 루어지고 있는 경증 중등도의 척추 변형이 있는 척추 측만증 환자들을 대상으로 나이, 신장, 체중, 근육량, 신체질량지수(Body Mass Index: 이하 BMI)를 고려한 상태에서 방사선학적 지표와 폐기능 및 흡기 능력의 관련성을 검증하고자 한다.

\section{연구 방법}

\section{연구대상}

본 연구의 대상자는 특발성 척추측만증으로 서울소 재 $\mathrm{K}$ 센터를 방문한 환자들을 대상으로 하였다. 연구 대상자는 총 59명 중 연구목적에 부합하지 않은 대상 자 28 명 [남자 11명, 흥요부(thoracolumbar)에 콥스 각이 있는 환자 4 명, 흥추의 콥스 각이 $40^{\circ}$ 이상인 환 자 9 명, 요부의 콥스 각이 $40^{\circ}$ 이상인 환자 1 명, 요추 에만 콥스 각이 있는 만곡을 가진 환자 3 명] 을 제외 하고 경증 중등도의 척추측만증 환자 중 여성으로 우 측 흥부 만곡(right thoracic curve)에 주요 만곡이 있 는 사람 31명으로 구성하였다. 흥부에 주요 만곡이 있 는 척추측만증 환자들을 대상으로 구성한 배경은 척 추측만증 환자의 폐기능이 흥추의 변형과 관련되어 있다는 Huh et al.(2015)의 보고를 고려한 것이었다.

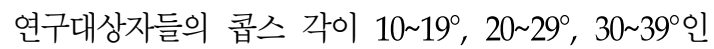
경우는 각각 6명(19.4\%), 13명(41.9\%), 12명(38.7\%)이었 으며, 구체적인 신체적 특성은 <Table 1 >과 같았다. 
Table 1. Physical characteristics of subjects

\begin{tabular}{ccccc}
\hline Age(yrs.) & Height $(\mathrm{cm})$ & Weight $(\mathrm{kg})$ & $\begin{array}{c}\text { Muscle } \\
\text { Mass }(\mathrm{kg})\end{array}$ & BMI $\left(\mathrm{kg} / \mathrm{m}^{2}\right)$ \\
\hline \hline $16.42 \pm 4.31$ & $158.98 \pm 7.27$ & $48.50 \pm 8.31$ & $18.76 \pm 2.51$ & $19.06 \pm 2.24$ \\
\hline
\end{tabular}

Means \pm SD

본 연구는 동신대학교 윤리위원회로부터 승인되었다 (승인번호: 1040708- 201510-BM-003-01).

\section{측정 및 검사}

\section{1. 신장, 체중, 근육량 및 $\mathrm{BMI}$}

신장, 체중, 근육량은 Inbody 230 모델(Biospace, Korea)를 이용하여 측정하였다. 신장과 체중은 대상자가 눈과 턱이 수평위치에 있도록 맞추고, 가벼운 옷차림으로 직립자세를 취한 후 신장은 $0.1 \mathrm{~cm}$ 단위까지 체중은 $0.1 \mathrm{~kg}$ 단위까지 측정하였다. 근육량은 Inbody 230 모델을 이용 하여 다주파수를 이용한 생체전기저항법으로 측정하였다. $\mathrm{BM}$ 는 측정한 신장과 체중을 이용하여 환산하였다.

\section{2. 방사선학적 지표의 측정}

척추측만증에 의한 신체 변형과 관련된 변인은 방 사선 검사를 통해 측정하였다. 방사선 검사는 서울 소 재의 $\mathrm{B}$ 병원에서 촬영하였으며, 방사선 촬영 전 대상 자들에게 X-ray 촬영 시 주의사항을 설명 후 척추 전 체를 standard standing anteroposterior and lateral view 방식으로 동일한 방사선사에 의해 측정되었다. 방사선 검사를 통해 흥부와 요부의 콥스 각, 어깨 기 울기, 골반 높이 차이, 흥추 후만각, 그리고 관련된 척 추의 수를 측정하였다. 각각의 변인들에 대한 구체적 인 측정방법은 다음과 같았다.

\section{1) 흥부의 콥스 각}

콥스 각은 X-ray 검사 결과로 측정하였다. 콥스 각 은 <Figure $1>$ 과 같이 측정하려는 만곡의 오목한 방향 으로 가장 많이 기울어진 상하부 척추를 결정한 후, 상부 끝 척추의 상단과 하부 끝 척추의 하단에 그은 뒤 각 선에서 직각으로 선을 그어 교차된 각을 구하여 측정하였다(Ardran et al., 1980; Deacon et al., 1984).

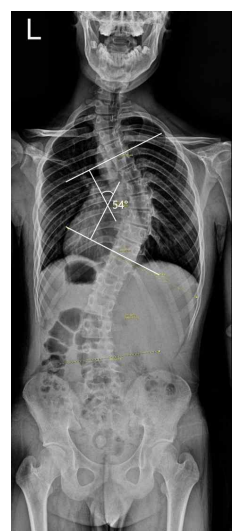

Figure 1. The Cobb's method of measuring the degree of scoliosis

\section{2) 어깨 기울기}

어깨 기울기는 X-ray 검사 결과로 측정하였다. 어깨 기울기는 <Figure 2>에서 보는 바와 같이, 수평선과 양측 쇄골의 기울어진 선 간의 각도를 측정한 쇄골 각(clavicle angle)으로 측정하였다(Qiu et al., 2009).

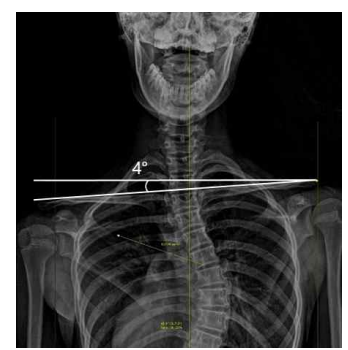

Figure 2. Measurement of shoulder tilt angle

\section{3) 골반 높이 차이}

골반의 높이 차이는 X-ray 검사 결과로 측정하였 다. 장골의 길이 차이는 <Figure $3>$ 에서 보는 바와 같이 Gonstead 분석법을 이용하여 측정하였다. 장골 의 길이 차이는 장골능의 최상단점과 좌골결절의 최

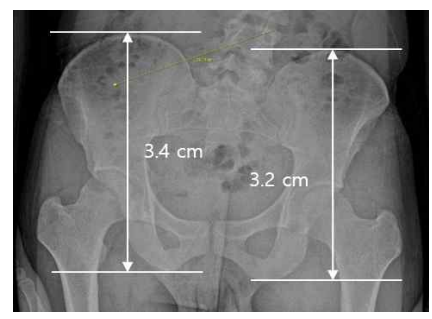

Figure 3. Measurement of pelvic height difference 
하단점간의 수직거리를 측정하여 좌·우측을 비교하 였다(Roger \& Herbst, 1980).

4) 흥추 후만각(angle of thoracic kyphosis)

흥추 후만각은 <Figure $4>$ 에서 보는 바와 같이 콥 (Cobb)의 방법을 수정하여 제 3번 흥추의 상단과 제 11 번 흥추의 하단에 선을 그었다. 그리고 각각의 선에 수 직선을 다시 그리고 수직선이 교차하는 각으로 흥추 후 만각을 측정하였다(Fon et al., 1990; Singer et al., 1990).

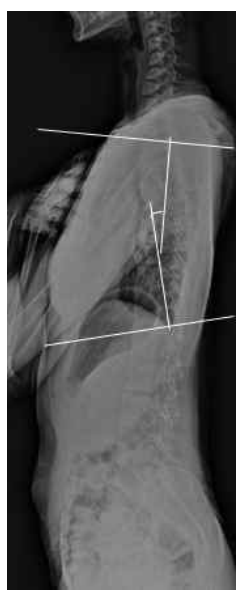

Figure 4. Measurement of thoracic kyphosis

5) 척추측만증과 관련된 척추의 수(number of vetebrae involved)

관련된 척추의 수는 콥스 각 측정 시 결정되었던 오목한 방향으로 가장 많이 기울어진 상부 흥추부터 하부 흥추까지의 척추의 개수를 측정하였다(Keenan et al., 2014).

\section{3. 폐기능 및 흡기 능력}

폐가능과 흡기 능력은 POWERbreathe-K5(POWERbr-eathe International Ltd, United Kingdom)을 이용하여 측정하였다.
측정방법은 선행연구(Kim, 2015)와 제작사(POMERbreathe International Ltd, United Kingdom)에서 제공한 사용설명서를 참고하였다. 측정 자세는 배와 가슴을 위로 하고 반듯하게 누 워서 가능한 범위에서 정렬상태를 바르게 하고 긴장을 푼 상 태에서 몸 안에 모든 공기를 밖으로 내보낸 후, 코를 사용하지 않고 입으로만 최대한 깊고 빠르게 숨을 들여 마시게 하였다. 평가는 3회 연습 후 15 회간 최대 흡기를 유도하여 측정하였다. 폐가능은 최대 흡기랭(maximum volume)으로 측정하였으며 흡기 능력은 흡기 시 최대 압력(strength index)과 최대 흡기 유속(peak inspiratory flow. 이하 PIF)으로 측정하였다.

\section{4. 자료분석}

자료분석은 Window SPSS version 21.0 프로그램 을 이용하였다. 폐기능에 영향을 줄 수 있는 신체적 특성과 관련된 변인이 무엇인지를 파악하기 위해 폐 기능과 나이, 신장, 체중, 근육량, BMI의 Pearson's correlation 분석을 실시하였다. 상관분석 후 폐기능 및 흡기 능력과 관련된 신체적 특성과 관련된 변인을 통제변인으로 설정한 후, 방사선학적 변인과 폐기능 및 흡기 능력 간의 Partial correlation 분석을 하였으 며, 유의수준은 .05 로 설정하였다.

\section{결과}

\section{1. 척추측만증 환자의 폐기능, 흡기 능력과 신체적 요인의 관계}

연구대상자들의 폐기능 및 흡기 능력과 관련된 변인 의 기술통계 결과는 <Table $2>$ 와 같았다. <Table $2>$ 에 서 보는 바와 같이 최대 흡기량의 평균표준편차는 $74.47 \pm 1266 \ell$ 였으며, 흡기 시 최대 압력과 $\mathrm{PIF}$ 의 평균 \pm 표준편차는 각각 $58.83 \pm 7.67 \mathrm{cmH} 2 \mathrm{O}, 3.34 \pm .48 \ell / \mathrm{s}$ 였다.

Table 2. Descriptive statistics of pulmonary function and inspiration ability

\begin{tabular}{lccccccc}
\hline & Unit & Minimum & Maximum & Mean & Standard deviation \\
\hline \hline Pulmonary function & Session maximum $(\mathrm{n}=31)$ & $\ell$ & 40.55 & 101.63 & 74.47 & 12.66 \\
\hline \multirow{2}{*}{ Inspiration ability } & Strength index $(\mathrm{n}=23)$ & $\mathrm{cmH} 2 \mathrm{O}$ & 42.15 & 75.75 & 58.83 & 7.67 \\
\cline { 2 - 8 } & $\mathrm{PIF}(\mathrm{n}=23)$ & $\ell / \mathrm{s}$ & 2.39 & 4.23 & 3.34 & .48 \\
\hline
\end{tabular}


나이, 신장, 체중, 근육량, $\mathrm{BMI}$ 와 폐기능 및 흡기 능 력의 Pearson correlation 분석 결과는 <Table $3>$ 과 같 았다. <Table 3>에서 보는 바와 같이, 폐기능과 관련된 최대 흡기량은 나이, 신장, 체중, 근육량, $\mathrm{BMI}$ 와 유의한 상관관계가 없었다. 그러나 흡기 능력과 관련된 흡기 시 최대 압력과 PIF는 신장을 제외한 나이, 체중, 근육 량, $\mathrm{BMI}$ 와 유의한 상관관계를 가지고 있었다(ㅈ.05).

\section{2. 척추측만증 환자의 폐기능, 흡기 능력과 방사선학적 지표의 관계}

척추측만증 환자의 방사선 촬영을 통해 측정한 척 추 변형 관련 방사선학적 지표들의 최소값, 최대값, 평균 및 표준편차는 <Table $4>$ 와 같았다.

척추측만증 환자의 신체적 요인은 <Table 3>에서 보는 바와 같이 폐기능과 상관관계가 없었기 때문에
척추 변형과 관련된 방사선학적 지표와 폐기능의 관 계는 Pearson correlation을 이용하여 분석하였으며, 그 결과는 <Table 5>와 같았다. <Table 5>에서 보는 바와 같이 척추 변형 관련 방사선학적 지표와 폐기능 간에 유의한 상관관계는 없었다.

척추측만증 환자의 신체적 요인은 <Table 3>에서 보는 바와 같이 흡기 능력과 상관관계가 있었기 때문 에 방사선학적 지표와 흡기 능력의 관계는 나이, 체 중, 근육량, 그리고 $\mathrm{BMI}$ 를 통제한 상태에서 Partial correlation을 이용하여 분석하였다. Partial correlation 분석 결과는 <Table 5>과 같았으며, <Table 5>에서 보는 바와 같이 척추 변형과 관련된 방사선학적 지표 와 흡기 능력 간에 유의한 상관관계는 없었다.

Table 3. Relation of physical pulmonary function and inspiration ability to physical characteristics

\begin{tabular}{|c|c|c|c|c|c|c|}
\hline & \multirow{2}{*}{\multicolumn{2}{|c|}{$\begin{array}{c}\text { Pulmonary function } \\
\text { Session maximum }(\mathrm{n}=31)\end{array}$}} & \multicolumn{4}{|c|}{ Inspiration ability } \\
\hline & & & \multicolumn{2}{|c|}{ Strength index $(n=23)$} & \multicolumn{2}{|c|}{$\mathrm{PIF}(\mathrm{n}=23)$} \\
\hline & $r$ & $p$ & $r$ & $p$ & $r$ & $p$ \\
\hline Age(yrs.) & (144 & NS & 2.464 & .026 & .422 & .045 \\
\hline Height $(\mathrm{cm})$ & .244 & NS & .285 & NS & .250 & NS \\
\hline Weight(kg) & .177 & NS & .429 & .041 & .446 & .033 \\
\hline Muscle mass $(\mathrm{kg})$ & .162 & NS & .514 & .012 & .490 & .018 \\
\hline $\mathrm{BMI}\left(\mathrm{kg} / \mathrm{m}^{2}\right)$ & .080 & NS & .441 & .029 & .484 & .019 \\
\hline
\end{tabular}

$r=$ Pearson correlation coefficient. $p$ Fsignificance value. NS=not significant. PIF=peak inspiratory flow.

Table 4. Descriptive statistics of radiological index

\begin{tabular}{lccccc}
\hline & Unit & Minimum & Maximum & Mean & Standard deviation \\
\hline \hline Thoracic Cobb's angle $(\mathrm{n}=31)$ & degree & 10.00 & 38.00 & 25.94 & 7.76 \\
\hline Shoulder tilt angle $(\mathrm{n}=31)$ & degree & .50 & 5.80 & 2.43 & 1.58 \\
\hline Difference of pelvic level $(\mathrm{n}=31)$ & $\mathrm{cm}$ & 0 & 6 & 1.71 & 1.41 \\
\hline Thoracic kyphosis $(\mathrm{n}=23)$ & degree & 13.00 & 22.00 & 19.04 & 2.42 \\
\hline Number of vetebrae involved $(\mathrm{n}=23)$ & Number & 6.00 & 9.00 & 7.35 & .98 \\
\hline
\end{tabular}

Table 5. Relation of pulmonary and inspiration ability to radiological index

\begin{tabular}{ccccccc}
\hline & \multicolumn{2}{c}{ Pulmonary function } & \multicolumn{3}{c}{ Inspiration ability } \\
\cline { 2 - 7 } & \multicolumn{2}{c}{ Session maximum } & \multicolumn{2}{c}{ Strength index } & \multicolumn{2}{c}{ PIF } \\
\cline { 2 - 7 } & $r_{1}$ & $p$ & $r_{2}$ & $p$ & $r_{2}$ & $p$ \\
\hline \hline Shoulder tilt angle & .048 & $\mathrm{NS}$ & .512 & $\mathrm{NS}$ & .529 & $\mathrm{NS}$ \\
\hline Difference of pelvic level & .054 & $\mathrm{NS}$ & .005 & $\mathrm{NS}$ & -.103 & $\mathrm{NS}$ \\
\hline Thoracic Cobb's angle & .223 & $\mathrm{NS}$ & .396 & $\mathrm{NS}$ & .502 & $\mathrm{NS}$ \\
\hline Lumbar Cobb's angle & .159 & $\mathrm{NS}$ & .040 & $\mathrm{NS}$ & -.038 & $\mathrm{NS}$ \\
\hline Thoracic kyphosis & .192 & $\mathrm{NS}$ & -.006 & $\mathrm{NS}$ & -.120 & $\mathrm{NS}$ \\
\hline
\end{tabular}

$r_{1}=$ Pearson correlation coefficient. $r_{2}=$ Partial correlation coefficient. $p=$ significance value. NS=not significant. PIF=Peak inspiratory flow. 


\section{논의}

특발성 척추측만증 중에 흥추에 만곡이 있는 측만증 은 심각한 폐기능의 손상과 조기 사망을 유발할 수도 있는 것으로 알려져 있지만, 그 원인이 되는 요인에 대 한 것은 많이 알려져 있지 않고 있다(Kearon et al., 1993). 척추측만증 환자들 중 흥추에 만곡이 있는 환자 들의 폐기능에 대한 연구는 오랜 전부터 이루어져 왔다.

척추측만증 환자의 폐기능에 관한 연구들은 주로 호 기 시 측정되는 폐활량(forced vital capacity or vital capacity), 폐활량을 기준으로 1 초 동안 강제호기한 공 기량의 비율인 1 초율, 예측된 폐활량에 대한 \% 등의 변인들을 이용하여 평가되어 왔다. 그러나 흡기 능력 은 많은 연구에서 중요한 폐기능과 관련된 주요 변인 으로 이용되고 있다. Diaz et al.(2000), Metin et al.(2007)과 Shen et al.(2010)은 폐쇄성 폐질환자의 폐 기능과 관련된 연구에서 흡기 능력(inspiratory capacity)을 주요 변인 중의 하나로 이용하였다. Smyth et al.(1984)은 경도 특발성 척추측만증 환자를 대상을 한 연구에서 척추측만증 호흡근에 의해 생성 되는 최대 흡기 압력(maximum inspiratory pressure) 은 강제호기량(forced vital capacity)과 상관관계가 있 다고 보고하였다.

본 연구에서는 흡기 시의 최대 공기량으로 폐기능 을 측정하였으며, 추가적으로 흡기 능력을 측정하였 다. 이는 2 가지 점을 고려한 것이었다. 첫째는 선행연 구(Diaz et al, 2000; Metin et al., 2007; Shen et al., 2010; Smyth et al., 1984)와 Kim et al.(2005b)의 연구 를 고려한 것이었다. Kim et al.(2005b)은 척수 손상환 자들을 대상으로 규칙적인 흡기근 트레이닝을 적용한 결과, 척추측만증과 폐기능이 개선되었다고 하였으며, 최대 흡기압력(maximum inspiration pressure)을 폐 기능과 관련된 변인 중 하나로 보고하였다. 본 연구자 들은 이러한 선행연구를 토대로 흡기 능력을 척추측 만증과 관련되어 있는 폐기능으로 판단하였다.

둘째는 흡기 시 가장 큰 기여를 하는 횡격막 (diaphragm)을 고려한 것이었다. 횡격막은 흡기 시 동원되는 근육 중 가장 큰 역할을 한다(Ratnovsky \& Elad, 2005). 또한 횡격막은 코어 안정화(core stability) 근육으로 분류되는데, 코어 안정화는 신체활 동에 있어서 최적의 신체분절 움직임과 힘의 생산, 조 절 및 전달을 허용하기 위한 골반 위에서의 몸통 움 직임과 위치를 조절하는 능력이다(Kibler et al., 2006). 따라서 횡격막이 몸통의 안정화 및 조절에 있어서 많 은 기여를 하고 있다고 할 수 있다. 척추측만증 환자 는 척추의 움직임과 조절에 문제가 있기 때문에 횡격 막을 이용한 호흡이 중요할 수 있다고 판단하였다.

$\mathrm{Xu}$ et al.(2015)는 40 91 의 콥스 각이 있는 청소년 특발성 척추측만증 환자들을 대상으로 한 연구에서, $\mathrm{BMI}$ 가 청소년 특발성 척추측만증 환자의 폐기능에 있어서 중요한 지표라고 하였으며, BMI가 폐기능 손 상의 약 $1 / 5$ 을 설명할 수 있다고 하였다. Feng et al.(2010)은 정상적인 폐기능을 가지고 있는 성인의 $\mathrm{BMI}$ 가 흡기 능력(inspiratory capacity)과 정적 상관관 계가 있다고 보고하였다. 본 연구는 심한 척추측만이 있는 환자들을 대상으로 했던 Xu et al.(2015)와는 달 리 10 39 의 콥스 각을 가지고 있는 척추측만증 환자 들을 대상으로 한 연구였다. 또한 Feng et al.(2010)와 는 달리 척추측만증 환자를 대상으로 한 연구였다. 본 연구에서 폐기능을 의미하는 최대 흡기량은 나이, 신 장, 체중, 근육량, $\mathrm{BMI}$ 와 유의한 상관관계가 없었다. 그러나 흡기 능력과 관련된 흡기 시 최대 압력과 PIF 는 신장을 제외한 나이, 체중, 근육량, $\mathrm{BM}$ 와 유의한 상관관계를 가지고 있었다(p夭.05). 이러한 결과는 선행 연구(Feng et al., 2010; Xu et al., 2015)와 부분적으로 관련되어 있다고 판단된다. 따라서 선행연구(Feng et al., 2010; Xu et al., 2015)와 본 연구결과를 볼 때, 척 추측만증 환자의 폐기능 평가와 관련해서 $\mathrm{BMI}$ 는 고 려되어야 할 요인인 것으로 생각된다.

척추 변형 관련 방사선학적 지표와 폐기능 및 흡기 능력 간에 유의한 상관관계는 없었다. 이러한 결과는 폐기능과 척추 변형 간에 관련이 있다는 선행연구들 (Fujii et al., 2014; Huh et al., 2015; Kim et al., 2005a; Newton et al., 2007; Upadhyay et al., 1995)과 상이한 결과였다. 이러한 차이는 연구대상자들의 척추 측만증 정도와 관련되어 있는 것으로 생각된다. 선행 연구들(Fujii et al., 2014; Kim et al., 2005a; Newton et al., 2007)은 수술적 치료를 받은 특발성 척추측만증 환자들을 대상으로 하였다. 척추측만증의 수술적 치료 
는 성장기이면서 콥스 각이 $45^{\circ}$ 를 초과하는 경우 또는 성장이 멈췄지만 콥스 각이 $50^{\circ}$ 를 초과하는 경우에 적 용할 수 있다(Scoliosis Research Society, 2015)는 점들 을 고려해 볼 때, 이러한 연구들은 매우 심한 척추 변 형이 있는 환자들이었다. Upadhyay et al.(1995)와 Huh et al.(2015)도 매우 심한 척추측만증 환자들을 대 상으로 한 연구로 연구대상자들의 평균 콥스 각은 각 각 $59^{\circ}, 53^{\circ}$ 였다. 그러나 본 연구는 $40^{\circ}$ 미만의 척추측 만증을 가지고 있는 환자들을 대상으로 한 연구였다. 본 연구의 연구대상자 수가 많지 않았음을 고려할 때, 단정할 수는 없지만 경증 중등도의 척추측만증은 폐기 능에 영향을 미치지 않을 수도 있을 것으로 생각된다. Yamaguchi(1984)도 $40^{\circ}$ 미만의 척추 변형이 있는 경우, 잔기량(residual volume), 기능적 잔기량(functional residual capacity)은 증가하고, 정적 폐탄성(static lung compliance)는 감소되지만, 폐활량(vital capacity)은 정 상 범위로 남아있다고 보고하였다. 만일 경증 중등도 의 척추측만증이 폐기능에 영향을 미치지 않는다면, 운 동전문가가 경증 중등도의 척추측만증을 가지고 있는 대다수의 환자와 부모에게 폐기능의 감소 등에 대한 정보를 제공하는 것은 왜곡된 정보를 제공하는 것일 수 있다. Lin et al.(2001)은 척추측만증 환자의 폐기능 손상의 정도를 예측할 수 있는 단일 요인은 없다고 하 였다. 이러한 선행연구(Lin et al., 2001)를 볼 때, 운동 치료적 접근이 이루어지고 있는 경증 중등도 척추측만 증 환자의 폐기능 손상은 매우 작을 수도 있으며, 폐기 능 감소는 여러 가지 요인들이 작용한 결과일 수도 있 다. 따라서 경증 중등도 척추측만증 환자의 운동치료 효과와 관련된 연구에서 폐기능을 주요 변인으로 다루 는 것을 신중하게 재검토해야 할 필요가 있다. 추후 척 추측만증의 폐기능 감소에 영향을 주는 요인들 또는 폐기능 손상에 영향을 줄 수 있는 신체 변형의 역치점 등에 대한 연구가 필요할 것으로 판단된다.

\section{결론 및 제언}

본 연구에서 콥스 각 $40^{\circ}$ 미만의 경증 중등도 척추측 만증에 해당되는 척추측만증 환자의 폐기능은 나이, 체
중, 근육량, 및 $\mathrm{BM}$ 와 관련되어 있었으며, 폐기능과 흡 기 능력은 방사선학적 지표들과는 관련되어 있지 않았 다. 따라서 임상가들과 운동전문가들이 콥스 각과 같은 방사선학적 지표를 이용하여 경증 중등도 척추측만증 환자에게 폐기능과 관련된 위험성을 경고하는 것은 적 절하지 않을 수도 있다. 추후 척추측만증에 의한 신체적 변형이 폐기능 손상을 일으키는 역치점이 존재하는지, 있다면 어느 정도의 변형이 폐기능 손상을 유발할 수 있는지에 관한 연구가 진행되어야 할 것으로 생각된다. 또한 경증 중등도 척추측만증 환자의 방사선학적 변형 만으로 폐기능과 흡기 능력을 예측하기는 어렵다.

\section{참고문헌}

An, K. C., Park, D. H., Kong, G. M., Kim, J. Y., Jin, S. Y., \& Lee, W. S. (2015). Prevalence study of adolescent idiopathic scoliosis in ten-, eleven-year olds for 10 years. Journal of the Korean orthopaedic association, 50(1): 25-30.

Ardran, G. M, Coates, R., Dickson, R. A., Dixon-Brown, A, \& Harding, F. M. (1980). Assessment of scoliosis in children: Low does radiographic technique. British jaurnal of radidogy, 53: 146-147.

Barrios, C., Pérez-Encinas, C., Maruenda, J. I., \& Laguía, M. (2005). Significant ventilatory functional restriction in adolescents with mild or moderate scoliosis during maximal exercise tolerance test. Spine, 30(14): 1610-1615.

Chung, K. J. (2007). Prevalence of Addlescent Idiopathic Scoliosis through School Scremning. Unpublished doctoral dissertation, University of Korea, Seoul, Korea.

Deacon, P., Flood, B. M., \& Diskson, R. A. (1984). Idiopathic scoliosis in dimensions. A radiofaphic and morphometric analyis. Journal of bone and joint surgery. British 
volume, 66B: 509-512.

Diaz, O., Villafranca, C., Ghezzo, H., Borzone, G., Leiva, A., \& Milic-Emil, J. (2000). Role of inspiratory capacity on exercise tolerance in COPD patients with and without tidal expiratory flow limitation at rest. The European respiratory journal, 16(2): 269-275.

Dreimann, M, Hoffmann, M, Kossow, K., Hitzl, W., Meier, O., \& Koller, H. (2014). Scoliosis and chest cage deformity measures predicting impairments in pulmonary function: a cross-sectional study of 492 patients with scoliosis to improve the early identification of patients at risk. Spine, 39(24): 2024-2033.

Feng, K., Chen, L., Han, S. M. \& Zhu, G. J. (2010). Relationship of body mass index, fat free mass index, and fat mass index with inspiratory capacity in adults with normal lung function. Zhongguo yi xue ke xue yuan xue bao, 32(1): 85-89.

Fon, G. T., Pitt, M. J., \& Thies, A. C. Jr. (1990). Thoracoc kyphosis: Range in normal subjects. American journal of roentgendogy, 134(5): 979-983.

Fujii, T., Watanabe, K, Toyama, Y., \& Matsumoto, M. (2014). Pulmonary function recovery demonstrated by ventilation-perfusion scan after posterior vertebral column resection for severe adolescent idiopathic scoliosis: a case report. Spine, 39(19): E1190-1194.

Green, B. N., Johnson, C., \& Moreau, W. (2009). Is physical activity contraindicated for individuals with scoliosis? A systemic literature review. Journal of chiropractic medicine, 8, 25-37.

Huh, S., Eun, L. Y., Kim, N. K., Jung, J. W., Choi, J. Y., \& Kim, H. S. (2015). Cardiopulmonary function and scoliosis severity in idiopathic scoliosis children. Korean journal of pediatrics, 58(6): 218-223.
Kane, W. J. (1997). Scoliosis prevalence: A call for a statement of terms. Cinical arthopaedics and related research, 126: 43-46.

Kearon, C, Viviani, G. R., Kirkley, A, \& Killian, K. J. (1993). Factors determining pulmonary function in adolescent idiopathic thoracic scolisis. American review of respiratory disease, 148(2): 288-294.

Keenan, B. E., Izatt, M. T., Askin, G. N., Labrom, R. D., Pearcy, M. J., \& Adam, C. J. (2014). Supine to standing Cobb angle change in idiopathic scoliosis: the effect of endplate pre-selection. Scoliosis, http://www.scoliosis journal.com/content/9/1/16.

Kibler, W. B., Press, J., \& Sciascia, A. (2012). The role of core stability in athletic function. Sports medicine, 36(3): 189-198.

Kim, Y. H. (2015). The effect of pulmonary function with thoracic mobility exercise and deep breathing exercise in stroke patients. Journal of Korean academy of orthopedic manual physical therapy, 21(1): 13-20.

Kim, Y. J., Lenke, L. G., Bridwell, K. H., Kim, K. L., \& Steger-May, K. (2005a). Pulmonary function in adolescent idiopathic scoliosis relative to the surgical procedure. The journal of bone and joint surgery. American volume, 87(7): 1534-1541.

Kim, Y. R., Cho, K. H., \& Kim, S. H. (2005b). Improvement of scoliosis and pulmonary function after resistive inspiratory muscle training in patients with spinal cord injury. Archives of physical medicine and rehabilitation, 86(9), e2.

Lee, D. Y., \& Hahn, M. S. (1971). Pulmonary function in kyphosis and scoliosis of the spine. Journal of the Korean arthopaedic association, 6(4): 361-364.

Lee, W. H. \& Kim, J. S. (2013). The effect of pulmonary function and Cobb's angle in the 
scoliosis patients after breathing exercise in several positions. Korean journal of growth and development, 21(1): 25-31.

Lin, M. C., Liaw, M Y., Chen, W. J., Cheng, P. T., Wong, A. M, \& Chiou, W. K (2001). Pulmonary function and spinal characteristics: their relationships in persons with idiopathic and postpoliomyelitic scoliosis. Archives of physical medicine and rehabilitation, 82(3): 335-341.

Machida, M. (1999). Cause of idiopathic scoliosis. Spine, 24(24): 2576-2583.

Metin, G., Oztürk, L., Duman, E. S., \& Demir, T. (2007). Exercise duration rather than peak oxygen uptake better correlates with Fev1 and inspiratory capacity in chronic obstructive pulmonary disease. Archives of medical research, 38(8): 876-81.

Newton, P. O., Faro, F. D., Gollogly, S., Betz, R. R., Lenke, L. G., \& Lowe, T. G. (2005). Results of preoperative pulmonary function testing of adolescents with idiopathic scoliosis. A study of six hundred and thirty-one patients. The journal of bone and joint surgery. American volume, 87(9): 1937-1946.

Newton, P. O., Perry, A., Bastrom, T. P., Lenke, L. G., Betz, R. R., Clements, D., \& D'Andrea, L. (2007). Predictors of change in postoperative pulmonary function in adolescent idiopathic scoliosis: a prospective study of 254 patients. Spine, 32(17): 1875-1882.

Park, S. E., Moon, H. H., \& Park, Y. J. (2013). The Effect of Schroth Treatment and Corrective Exercise on Cobb's Angle and Pulmonary Function Variables of Idiopathic Scoliosis Patients. Journal of Sport and Leisure Studies, 52(2): 777-788.

Park, S. Y., \& Shim, J. H (2014). Effect of 8 Weeks of Schroth Exercise(Three-dimensional Convergence
Exercise) on Pulmonary Function, Cobb's Angle, and Erector Spinae Muscle Activity in Idiopathic Scoliosis. Jaurnal of the Korea Convergence Society, 5(4): 61-68.

Qiu, X. S., Ma, W. W., Li, W. G., Wang, B., Yu, Y., \& Zhu, Z. Z. (2009). Discrepancy between radiographic shoulder balance and cosmetic shoulder balance in adolescent idiopathic scoliosis patients with double thoracic curve. European spine journal, 18(1): 45-51.

Ratnovsky, A., \& Elad, D. (2005). Anatomical model of the human trunk for analysis of respiratory muscles mechanics. Respiratory physiology and neurobiology, 148(3): 245-262.

Roger, W., \& Herbst, D. C. (1980). Anatomy and Ballet, In: Gosstead Ciropractic Science and Art, Spager, Celia, SCE-CHI. New York: Threatre Arts Books.

Scoliosis Research Society (2015). What Are My Treatment Options? http://www.srs.org/patient_and_family /what_are_my_treatment_options/surgical_treat ment.htm

Shen, N., Yao, W. Z., Liu, Z., Wang, X. H. Hao, Z. T., \& Liu, X. F. (2010). Correlation of the quality of life with the inspiratory capacity in patients with chronic obstructive pulmonary disease. Zhonghua jie he he hu $x i$ za zhi, 33(4): 261-264.

Singer, K P., Jones, T. J., \& Breidahl, P. D. (1990). A comparison of radiographic and computer-assisted measurements of thoracic and thoracolumbar sagittal curvature. Skeletal raddogy, 19(1): 21-26.

Smyth, R. J., Chapman, K. R., Wright, T. A, Crawford, J. S., \& Rebuck, A S. (1984). Pulmonary function in adolescents with mild idiopathic scoliosis. Thorax, 39(12): 901-904.

Tantucci, C., Donati, P., Nicosia, F., Bertella, E., Redolfi, S., \& De Vecchi, M. (2008). Inspiratory capacity predicts mortality in patients with chronic obstructive pulmonary disease. 
Respiratory medicine, 102(4): 613-619.

Upadhyay, S. S., Mullaji, A. B., Luk, K. D., \& Leong, J. C. (1995). Relation of spinal and thoracic cage deformities and their flexibilities with altered pulmonary functions in adolescent idiopathic scoliosis. Spine, 20(22): 2415-2420.

Weinstein, S. L. (1989). Adolescent idiopathic scoliosis: prevalence and natural history. Instructional course lectures, 38: 115-128.

Willner, S. (1984). Development of trunk asymmetries and structural scoliosis in prepuberal school children in Malmo: follow-up study of children 10-14 years of age. Journal of pediatric arthopedics, 4: 452-455.
Xu, L., Sun, X., Zhu, Z., Qiao, J., Mao, S., \& Qiu, Y. (2015). Body Mass Index as an Indicator of Pulmonary Dysfunction in Patients With Adolescent Idiopathic Scoliosis. Jaurnal of spinal disorders and techniques, 28(6): 226-231.

Yamaguchi, C. (1984). Pulmonary function and movement of the thoracic cage in mild idiopathic thoracic scoliosis. Nihan Seikeigeka Gakkai Zasshi, 58(10): 989-1002.

Yetkin, O., \& Gunen, H. (2008). Inspiratory capacity and forced expiratory volume in the first second in exacerbation of chronic obstructive pulmonary disease. The clinical respiratory journal, 2(1): 36-40. 